\title{
What is Sustainable Development?
}

\author{
Linda J. Cox ${ }^{1}$ and John Cusick ${ }^{2}$ \\ ${ }^{1}$ CTAHR Department of Natural Resource Management, ${ }^{2}$ UH Mānoa Environmental Center
}

$\mathrm{T}$ he terms "sustainable development" and "sustainability" are being used more and more recently, but these concepts are not new. Most traditional agricultural systems are based on principles of sustainable yields. Indigenous cultures around the world struggle to maintain their agro-ecosystems and ways of life through sustainable practices.

Communities worldwide, both rural and urban, have become interested in using participatory problem-solving and conflict-resolution approaches for reaching agreement on how scarce resources should be used. When communities desire sustainable approaches to resource utilization, problems may be harder to solve, and the conflict between ideals may be greater.

Industrialization and globalization have changed the world. These trends have ushered in complex economic systems, and they frequently occur at the expense of biological and cultural diversity. The decline in diversity has increased the desire to protect the environment, preserve cultural values, and provide social equity.

Many definitions of sustainable development can be found. In general, sustainable development means development that meets the needs of people today without compromising the ability of people in the future to meet their needs. Planning for this type of development and actually achieving it is a complex task. Individuals, communities, governments, and non-governmental organizations around the world have been working on programs associated with the components of sustainable development for many decades. A report developed by the 1987 World Commission on Environment and Development identified key components of sustainable development, listed in Table 1.
Sustainability integrates social, environmental, and economic systems, as illustrated in the diagram below. The sustainability components listed in Table 1 relate to issues from each of these three systems. Some of the issues (e.g., population control) involve social systems, while others (e.g., species diversification), center on environmental systems. The most complex issues are those involving interactions between two or all three of the systems. For example, the role of economic growth in promoting human well being includes the social and economic systems. Sustainability aims to achieve a harmony, or balance, in the interactions of the three systems, which is represented by the shaded area in the diagram. As the diagram shows, the area in which the interests of all three systems converge is small relative to the size of each system.

\section{Three systems for sustainability}

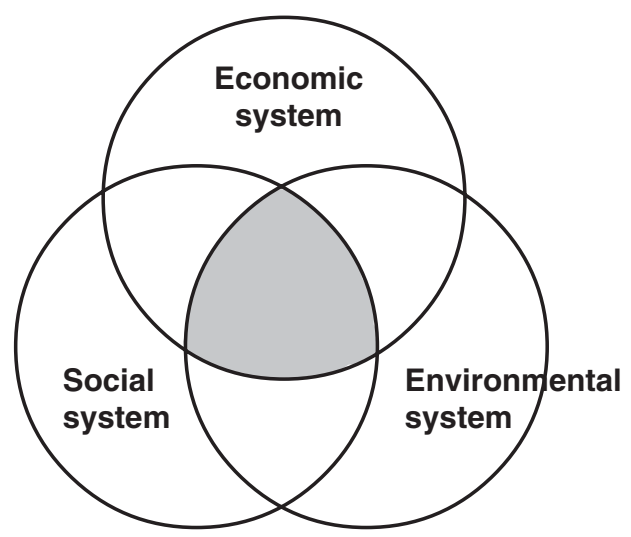

Published by the College of Tropical Agriculture and Human Resources (CTAHR) and issued in furtherance of Cooperative Extension work, Acts of May 8 and June 30,1914 , in cooperation with the U.S. Department of Agriculture. Andrew G. Hashimoto, Director/Dean, Cooperative Extension Service/CTAHR, University of Hawai'i at Mānoa, Honolulu, Hawai'i 96822. An equal opportunity/affirmative action institution providing programs and services to the people of Hawaili without regard to race, sex, age, religion, color, national origin, ancestry, disability, marital status, arrest and court record, sexual orientation, or status as a covered veteran. CTAHR publications can be found on the Web site <http://www.ctahr.hawaii.edu/freepubs> 


\section{Three broad system components of sustainability}

Because sustainability involves so many disparate issues, discussions of the relevant goals and objectives are often broad and may lack focus. Hunter (1997) argued that sustainable development is not a single absolute standard. He illustrated a wide spectrum of attitudes and levels of commitment (Table 2). From a sustainability perspective, these range from weak and humancentered to strong and "life"-centered.

Those who are strongly in favor of sustainable development prefer to have less consumption of non-renewable resources in the future, as compared with today's use. Examples of strongly sustainable communities in the state of Hawai' $i$ do not exist, but that is what existed throughout the Hawaiian Islands prior to the 1800s. In- dividuals traveled within and between islands by wind and human power, and food from local sources was consumed. In comparison, most of us today routinely travel in devices fueled by imported petroleum, and our food is, for the most part, imported. While our mobility has increased, so has our dependency on resources that are not from these islands.

Some people today see themselves as being resourceconservationist or resource-preservationist. However, others in the community are likely to be growth-oriented, particularly those in the business sector, because it generates jobs and funds the taxes to support government employees and programs. Currently, this is the dominant worldview. An alternative viewpoint that does not favor human resource use over ecological integrity may be criticized as unachievable. An individual's perspec-

\section{Table 1. Components of sustainable development.}

\section{Component}

Ecological limits and equitable standards

Economic activity and equitable resource allocation

Population control

Resource conservation

Carrying capacity and sustainable yield

Resource retention

Species diversification

Adverse impact minimization

Community control

Broad national/international framework

Economic viability

Environmental quality

Environmental audit
Goal

Encourage consumption that is ecologically possible for all

Ensure economic growth that allows all people to meet their needs

Prevent population from exceeding the productive potential of the ecosystem

Protect all natural systems

Identify the productive potential of the ecosystem

Reduce the rate of depletion for non-renewable resources

Conserve and protect plant and animal species

Prevent damage to the ecosystem caused by pollution

Prevent the exploitation and degradation of ecosystems

Jointly manage the biosphere

Pursue economic well being given government policies that limit growth

Make environmental quality a corporate goal

Track the progress of environmental management systems

(Source: World Commission on Environment and Development. 1987. Our common future. Oxford University Press, U.K.) 
tive may not always be absolute and may change depending on the situation, which is why education and critical thinking skills are so important to ensure fair and just resolution of current and future resource use concerns. Communities and their leaders can strive for sustainable outcomes in order to ensure that the future is not sacrificed for today.

Agreement on sustainable development is difficult to reach because so many hard choices have to be made. Sustainability is a very long-term community goal. Many people in Hawai' $i$ are focused on very short-term personal goals, such as paying the rent, or the mortgage, and other costs of living, which may be so great a challenge that they cannot think of much else. Further, some of the larger issues, such as identifying environmental carrying capacity, may require years of research, while in the meantime decisions are being made that affect the future. However, any progress that can be associated with the goals in Table 1 will move Hawai' $i$ closer to sustainability than no progress at all.
Communities across Hawai' $i$ are looking at specific sustainable development goals. The five "Ps" of sustainable development that address general areas in which actions will need to be taken are

Predictive modeling - Determine what interactions happen now within and between each system and what would be the impact of change.

Policy and planning - Identify appropriate actions for bringing about a more sustainable community.

Performance monitoring - Select benchmark indicators for each system that will allow progress toward sustainability goals to be measured.

Performance improvement-Agree on target ranges that realistically can be reached for each indicator.

Performance reporting-Evaluate progress toward sustainability on a regular basis and adjust the other variables as needed.

Table 2. A simple description of sustainability positions and characteristics.

\section{Position Defining characteristics}

Very weak Growth-oriented

Natural resources used to satisfy individual needs and desires

Substitution between natural and man-made capital

Continued human well being assured through economic growth and technical innovation

Weak Resource-conservationist

Growth is managed and modified

Concern for distributing development costs and benefits through intra- and inter-generational equity

Reject infinite substitution between natural and human-made capital with recognition that some aspects of the natural world are critical

Decouple negative environmental impacts from economic growth

Strong Resource-preservationist

Values maintaining ecosystems over human resource utilization

Interests of the collective over the interests of the individual

Adherence to intra- and inter-generational equity

Balanced economic and human population growth

Very strong Resource-preservationist to the point where natural resource use is minimized Against destructive economic growth; favors reduced human population

(Source: Hunter 1997, adapted from Turner et al. 1994) 
If you are interested in moving toward a more sustainable future, you can become more of a resource preservationist in your day-to-day life. You can work with organizations dedicated to the principles of sustainability. Many members of the University of Hawai' $i$ faculty are poised to work with stakeholder groups to ensure a transition to a more sustainable future. You can learn more about sustainability in Hawai'i by visiting the UH website http://sustainable-uh.hawaii.edu. Progress toward sustainability will not happen without broad participation from people concerned about the future being created by the economic, social, and environmental decisions that we are making today, consciously or unconsciously, or that are being made for us.

\section{Literature cited}

World Commission on Environment and Development. 1987. Our common future. Oxford University Press, U.K. (also known as "The Brundtland Report").

Hunter, C. 1997. Sustainable tourism as an adoptive paradigm. Annals of Tourism Research 24:850-867.

Turner, J. 1994. Natural Neighbor. BBC TV, October 22, 1994. 